\title{
URBAN GROWTH MODELING USING AN ARTIFICIAL NEURAL NETWORK A CASE STUDY OF SANANDAJ CITY, IRAN
}

\author{
S. Mohammady ${ }^{\text {a, *, M. R. Delavar }}{ }^{\text {b }}$ P. Pahlavani ${ }^{\mathrm{c}}$ \\ a,* GIS MSc. student, Dept. of Surveying and Geomatic Eng., College of Eng., University of Tehran, Tehran, Iran \\ ${ }^{\mathrm{b}}$ Center of Excellence in Geomatic Eng. in Disaster Management, Dept. of Surveying and Geomatics Eng., \\ College of Eng., University of Tehran, Tehran, Iran \\ ${ }^{c}$ Dept. of Surveying and Geomatic Eng., College of Eng., University of Tehran, Tehran, Iran \\ \{Sassanmohammady, mdelavar, pahlavani\}@ut.ac.ir
}

KEY WORDS: Urban Growth Modelling, GIS, ANN

\begin{abstract}
:
Land use activity is a major issue and challenge for town and country planners. Modelling and managing urban growth is a complex problem. Cities are now recognized as complex, non-linear and dynamic process systems. The design of a system that can handle these complexities is a challenging prospect. Local governments that implement urban growth models need to estimate the amount of urban land required in the future given anticipated growth of housing, business, recreation and other urban uses within the boundary. There are so many negative implications related with the type of inappropriate urban development such as increased traffic and demand for mobility, reduced landscape attractively, land use fragmentation, loss of biodiversity and alterations of the hydrological cycle. The aim of this study is to use the Artificial Neural Network (ANN) to make a powerful tool for simulating urban growth patterns. Our study area is Sanandaj city located in the west of Iran. Landsat imageries acquired at 2000 and 2006 are used. Dataset were used include distance to principle roads, distance to residential areas, elevation, slope, distance to green spaces and distance to region centers. In this study an appropriate methodology for urban growth modelling using satellite remotely sensed data is presented and evaluated. Percent Correct Match (PCM) and Figure of Merit were used to evaluate ANN results.
\end{abstract}

\section{INTRODUCTION}

World urban population has been dramatically increased from $22.9 \%$ in 1985 to $47 \%$ in 2010 (Jiang et al., 2012) which has caused an unprecedented urban environmental degradation and shortage of adequate urban infrastructure needed to support the population. Urban planners must be able to allocate urban land area to different applications with a special focus on the role and function of the city, its economy, and the ability to simulate the impacts of user interactions. Continuing migration of rural population to cities and population growth, the expansion of urban areas, lack of adequate infrastructure and urban services and environmental pollution are related to land use. The impact of piecemeal planning in large cities is often a major concern of stakeholders such as those involved in urban growth modelling, forecasting and policy making related to planning sustainable urban development. Urban growth is a complex process that encounters a number of sophisticated parameters that interact to produce the urban growth pattern. The problem analysis, planning and monitoring phases of sustainable urban management policies require reliable information on the urban environment and its dynamics. Geospatial and socio-economic data supplemented with knowledge on dynamic urban processes are incorporated in the land-use change models currently available to planners and policy makers. The data enable the urban planners and decision makers to assess the impacts of decisions on the urban dynamics. To be usefully applicable, the models need extensive calibration. Spatial land use models are indispensable for sustainable land use planning. Dynamic spatial urban models provide an improved ability to assess future urban growth and to create planning scenarios, allowing us to explore the impacts of decisions that follow different urban planning and management policies. In recent years, due to urban population growth and migration from cities to towns, inconsistencies between urban growth and exiting infrastructures have been occurred. Urban growth modelling aims to understand the dynamic processes and therefore, interpretability of models is becoming crucial.

\section{METHOD}

Different approaches have been attempted in spatial modelling. These models enable us to simulate and predict the complexities of urban growth. Artificial Neural network (ANN) models are knowledge-based models. ANNs are powerful tools that use a machine learning approach to quantify and model complex behaviour and patterns and ANN modelling is concerned with the extraction of models from numerical data representing the behavioural dynamics of a system. ANN has the great function of dealing with imprecise data by training. Artificial Neural network (ANN) is one of the meta-heuristic and knowledgebased models. Artificial Neural network structures can deal with imprecise data and ill-defined activities.

This task is carried out by a process of learning from samples presented to the ANN. Artificial Neural network due to the 
possibility of learning, is an appropriate tool for environmental modelling. This method has been used in land use change modelling by (Pijanowski et al., 2002, Tayyebi et al., 2011, Li and Yeh, 2001, Weng, 2002, Pijanowski et al., 2009). These networks are composed of input layer, intermediate layers and an output layer. This type of networks is used to identify nonlinear relationships as more practical issues faced by non-linear phenomena. Fig.1 shows a typical feed-forward back propagation ANN.

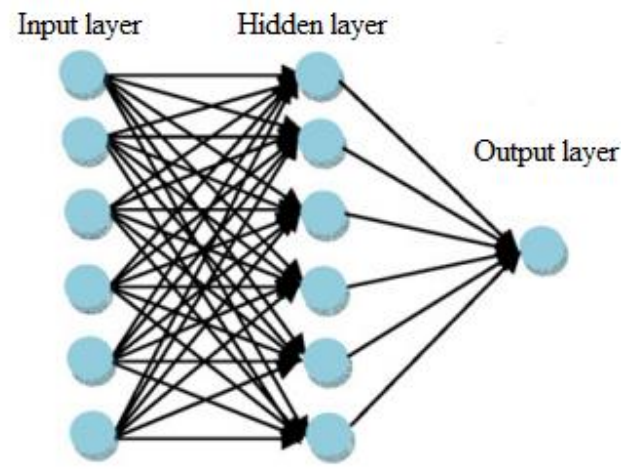

Fig. 1 A typical feed-forward back propagation ANN

2000

\subsection{Case study}

The study area in this research is Sanandaj city, in the west of Iran. In the past few decades, Sanandaj has shown remarkable urban growth. One of the reasons for the rapid population growth in this city is migration from neighboring cities and even from neighboring provinces to the city because of the economic and social potential of this city. In this study, two Landsat $\mathrm{TM}$ and $\mathrm{ETM}^{+}$satellite imageries with $28.5 \mathrm{~m}$ and $30 \mathrm{~m}$ spatial resolution acquired in 2000 and 2006 were used. Data were projected to World Geodetic System (WGS) 1984 , Universal Transverse Mercator (UTM) Zone 38N coordinate system. The 2000 and 2006 Landsat imageries were classified according to Anderson level 1 with ENVI software. Fig. 2 shows the classified imageries. Maximum Likelihood classification has been used to classify the imageries. Overall accuracy and kappa coefficient of these imageries were $92.57 \%$ and $89.17 \%$ for 2000 and $94.71 \%$ and $92.68 \%$ for 2006 , respectively.
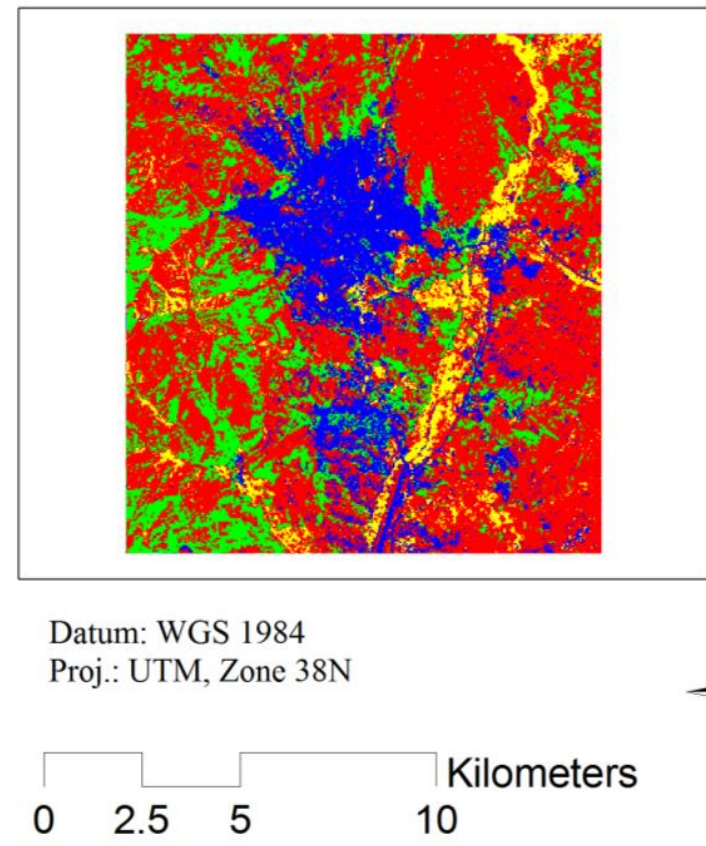

2006
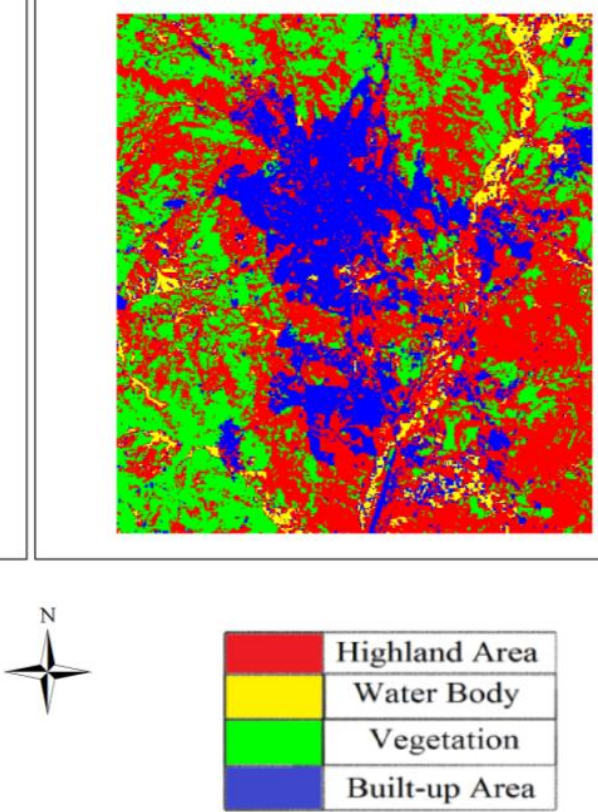

Fig. 2 The Classified imageries

We have used $20 \%$ of 2000 and 2006 imageries data for calibrating models and rest of the data have used to simulate the urban pattern at 2006. Datasets employed include six parameters include distance to main roads, distance to residential areas, elevation, slope, distance to green spaces and distance to region centers. Following (Pijanowski et al., 2002) normalized map have been used (Fig. 3). 
Distance to residential area

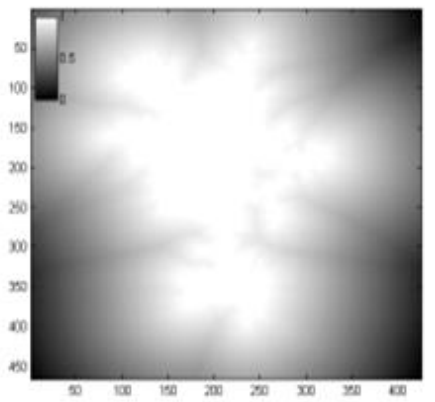

Distance to roads

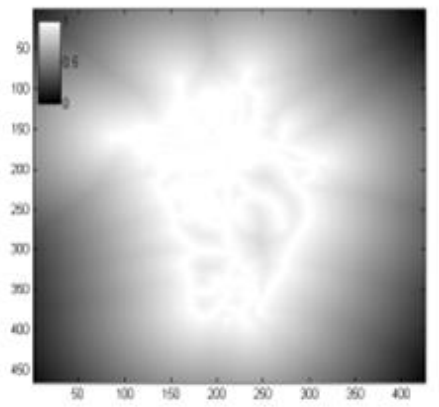

Slope

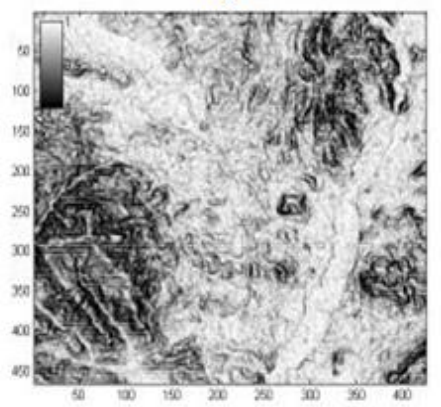

Elevation

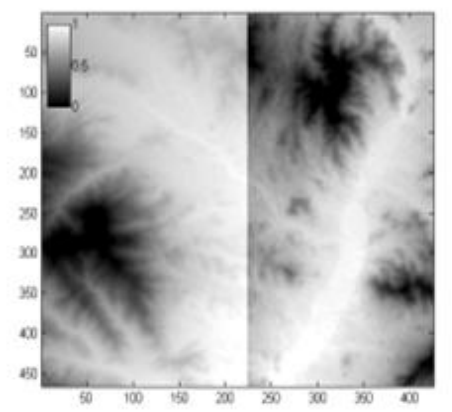

Distance to green space

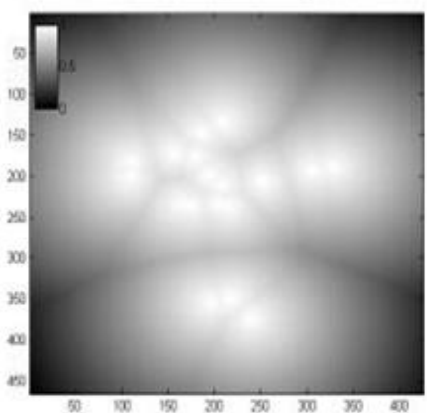

Number of urban cell in a 3*3 neighborhood
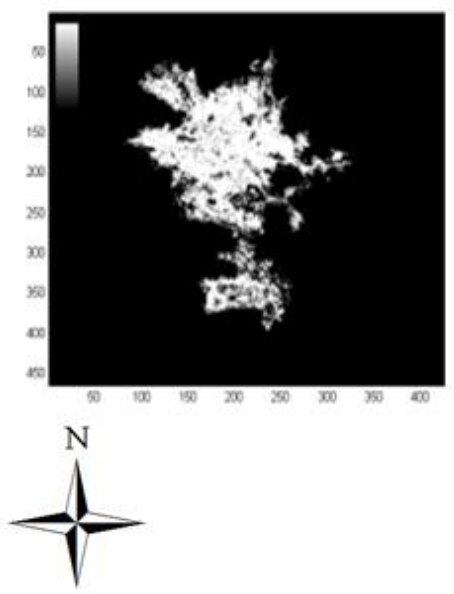

Kilometers

10

Datum: WGS 1984

Proj.: UTM, Zone $38 \mathrm{~N}$

Fig. 3 The normalized inputs

\section{RESULTS}

The implemented ANN is trained using $20 \%$ of the overall data. The rest of the data is used to compare the 2006 simulated map with real one. Fig. 4 shows the ANN MSE in 500 cycles. The proposed ANN structure has the 3 layer structure. The number of nodes in the first layer equal to the number of inputs.
This structure has 6 nodes in the first layer, 13 nodes in second layer and 1 node in the output layer. The checking error and training error has started under 0.3 and 0.37 respectively and after 500 epochs reached under 0.1 and 0.15 , respectively. 


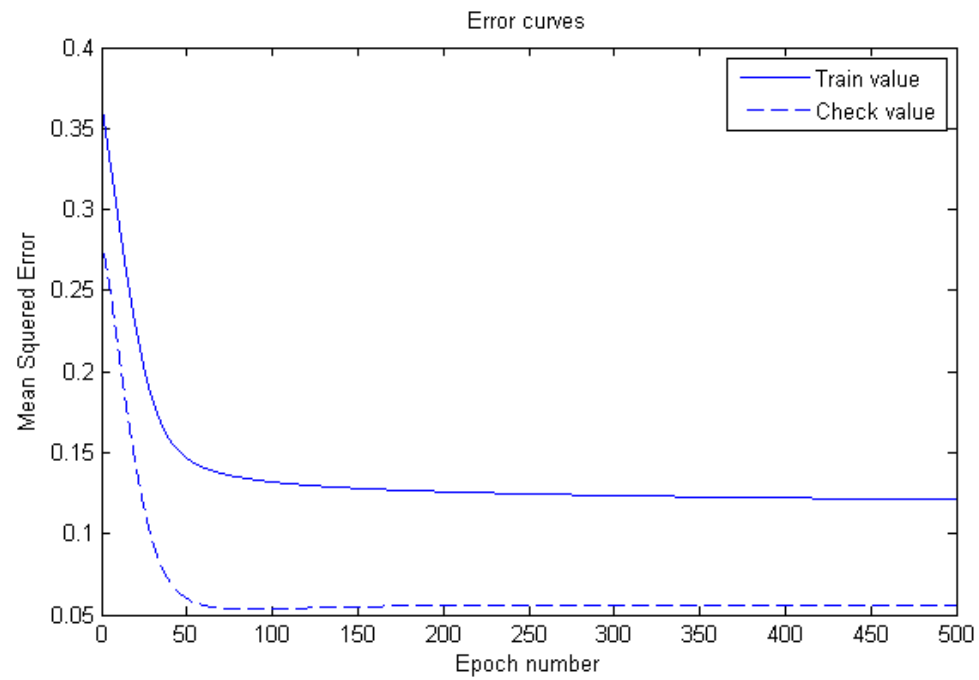

Fig. 4 ANN error curve

\subsection{Figure of Merit (FoM)}

Figure of Merit (Equation 1) is a method to evaluate resemblance between actual and simulated map suggested first time by (Pontius et al., 2008). If simulated map have a high goodness of fit to actual map, Figure of Merit will be high and vice versa.

Figure of Merit $=\frac{b}{a+b+c+d}$

where, $a=$ error due to observed change predicted as persistence, $b=$ correct due to observed change predicted as change, $c=$ error due to observed change predicted as wrong gaining category, $d=$ error due to observed persistence predicted as change.

\subsection{Percent Correct Match (PCM)}

Percent Correct Match (PCM) is a way to evaluate models of urban development. This method compares only the parameters of the original diameter of the $\mathrm{A}$ and $\mathrm{D}$ in the confusion matrix using Equation 2 (Table 1) (Pontius and Schneider, 2001). Table. 2 present the implemented confusion matrix. $P C M=\frac{A+D}{A+B+C+D}$

\begin{tabular}{|c|c|c|c|}
\hline Model & Reality & & \\
\hline \multirow{4}{*}{$\begin{array}{c}\text { Change } \\
\text { Non Change } \\
\text { Total }\end{array}$} & Change & Non Change & Total \\
\hline & A & B & $\mathrm{A}+\mathrm{B}$ \\
\hline & $\mathrm{C}$ & $\mathrm{D}$ & $\mathrm{C}+\mathrm{D}$ \\
\hline & $\mathrm{A}+\mathrm{C}$ & $\mathrm{B}+\mathrm{D}$ & $\mathrm{A}+\mathrm{B}+\mathrm{C}+\mathrm{D}$ \\
\hline
\end{tabular}

Table 1. Confusion matrix

\begin{tabular}{cccc}
\hline & & Reference Data 2006 & \\
\hline Simulated Data 2006 & Developed & Undeveloped & Total \\
Developed & & & \\
Undeveloped & $13694(\mathrm{TP})$ & $6348(\mathrm{FP})$ & 20042 \\
Total & $11255(\mathrm{FN})$ & $146566(\mathrm{TN})$ & 157821 \\
\hline
\end{tabular}

Table 2. Confusion matrix 
According to Table. 2, PCM is obtained equal to $90.10 \%$. The FoM obtained equal to $43.75 \%$. According to recent works

\section{Reference 2006 map}

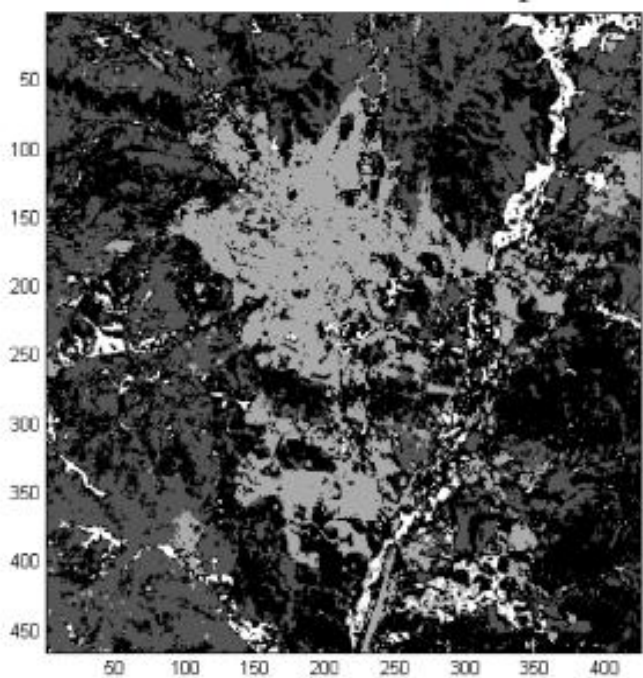

(Pontius et al., 2008) it seems to have a reasonable goodness of fit. Fig. 5 shows the result map.

\section{Simulated 2006 map using ANN}
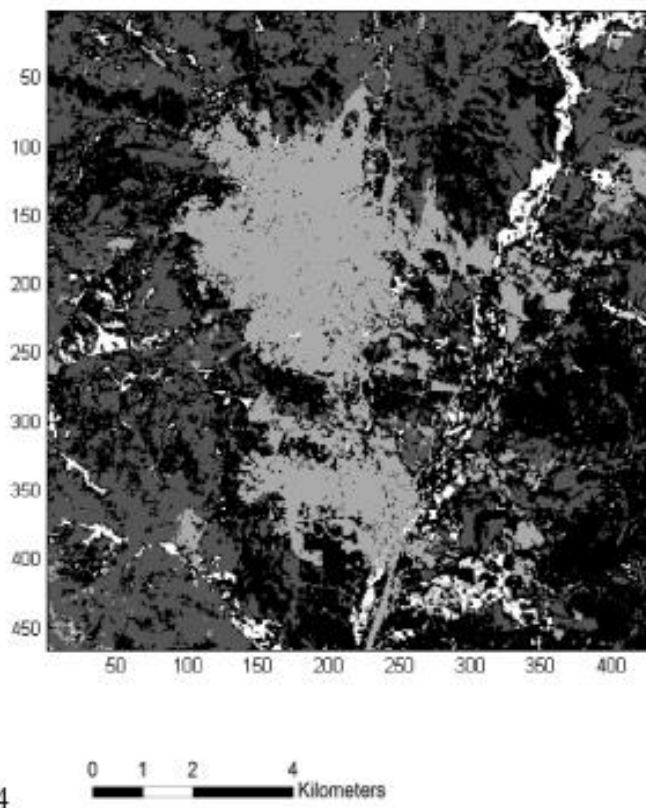
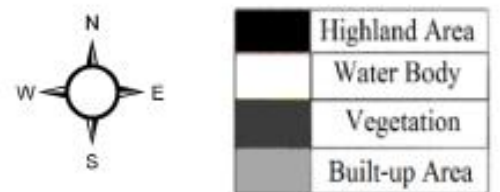

\section{Datum: WGS 1984}

Proj.: UTM, zone $38 \mathrm{~N}$

Fig. 5 The reference map and simulated 2006 map using ANN

\section{CONCLUSIONS}

According to Fig .2, urban growth in this city during 2000 to 2006 has occurred inclemently in south area of the city. Although, in other regions of city, urban growth have occurred, in south areas the growth were much more than others.

According to Fig.4, the slope and elevation map tell indicate exiting of high elevation area in west, southwest, north and northeast of the city which limit the growth of the city in these directions.

Integration of GIS, remote sensing data and ANN as a computational method, provides a strong method in environmental modelling such as urban growth modelling. ANN structure and advantages enable this method to perceive complex and nonlinear pattern between data.

In this paper we implement an ANN structure for modelling urban growth in Sanandaj city between 2000 and 2006 (Fig. 6). PCM and FoM are considered as the accuracy assessment equal to $90.10 \%$ and $43.75 \%$, respectively. According to (Pontius et al., 2008), FoM factor in this paper prove the accuracy of modelling and it seems the modelling urban growth for Sanandaj city, to be at a reasonable level.

\section{REFERENCE}

Jiang, L., X, Deng., K, C, Seto., Multi-level modeling of urban expansion and cultivated land conversion for urban hotspot counties in China, Landscape and Urban Planning 108 (2012) 131-139.
Li, X., Yeh, A., Calibration of cellular automata by using neutral networks for the simulation of complex urban systems, Environment and Planning A, 2001, 33 (4), 1445-1462.

Pijanowski, B.C, Tayyebi, A., M. R., Delavar, and M. J, Yazdanpanah, 2009, Urban Expansion Simulation Using Geospatial Information System and Artificial Neural Networks, Int. J. Environ. Res., 3(4):493-502,

Pijanowski, B.C., Brown, D.G., Shellito, B.A., and Manik, G.A., 2002, Using neural networks and GIS to forecast land use changes: a land transformation model. Comput. Environ. Urban $26(6), 553-575$

Pontius Jr., R.G., Boersma, W., Castella, J.C., Clarke, K., de Nijs, T., Dietzel, C., Zengqiang, D., Fotsing, E., Goldstein, N., Kok, K., Koomen, E., Lippitt, C.D., McConnell, W., Pijanowski, B., Pithadia, S., Sood, A.M., Sweeney, S., Trung, T.N., Veldkamp, and A.T., Verburg, P.H., 2008, Comparing the input, output, and validation maps for several models of land change. Annals of Regional Science, 42: 11 - 47.

Pontius Jr., R. G., and Schneider, L. C., 2001, Land-cover change model validation by an ROC method for the Ipswich watershed, Massachusetts, USA. Agriculture, Ecosystems \& Environment, 85(1-3), 239-248 
The International Archives of the Photogrammetry, Remote Sensing and Spatial Information Sciences, Volume XL-2/W3, 2014

The 1st ISPRS International Conference on Geospatial Information Research, 15-17 November 2014, Tehran, Iran

Tayyebi, A., Pijanowski, B.C., Tayyebi, A.H., An urban growth boundary model using neural network parameterization: An application to Tehran, Iran Landscape and Urban Planning, 2011, 100, 35-44.

Weng, Q., 2002. Land use change analysis in the Zhujiang delta of China using satellite remote sensing, GIS, and stochastic modeling. Journal of Environmental Management 64 (3), 273 284. 